\title{
Experiences of Psychiatric Day-Care Patients during the Introductory Period in Japan
}

\author{
Tomoko Chijiiwa*, Kayoko Ishimura \\ School of Nursing, Ichinomiya Kenshin College, Aichi, Japan \\ Email: ${ }^{\star}$ t.chijiiwa.t@ikc.ac.jp
}

How to cite this paper: Chijiiwa, T. and Ishimura, K. (2020) Experiences of Psychiatric Day-Care Patients during the Introductory Period in Japan. Open Journal of Therapy and Rehabilitation, 8, 29-41. https://doi.org/10.4236/ojtr.2020.83003

Received: May 12, 2020

Accepted: June 7, 2020

Published: June 10, 2020

Copyright $\odot 2020$ by author(s) and Scientific Research Publishing Inc. This work is licensed under the Creative Commons Attribution International License (CC BY 4.0).

http://creativecommons.org/licenses/by/4.0/

(c) (i) Open Access

\begin{abstract}
Psychiatric day care plays an important role as transitional support after discharge in Japan. However, interruption rate of the day care treatment is high during the introductory period. The purpose of this study was to clarify the experiences of psychiatric day-care patients during the introductory period and find an approach to care. A qualitative study with thirteen patients at the introductory period was designed to explore participant's experiences through semi-structured interviews. At first, patients were confused about their attitude because they paid attention to themselves, and consequently closed their involvement with others. However, through therapeutic day care activities, they attempted to adapt themselves and gradually turned their attention toward others and accumulated interpersonal experiences. As interactions with others became more frequent, they became conscious of themselves and others. Finally, while having worries about the future, they looked toward recovery and became aware that they were changing. Experiences of patients during the introductory period were essential to their recovery and gave meaning to their day care usage. Nurses should collaborate with patients to determine whether day care would serve to open a patient's life to new possibilities.
\end{abstract}

\section{Keywords}

Psychiatric Day Care, Experiences of Patients, Introductory Period, Qualitative Descriptive Analysis, Japan

\section{Introduction}

In 2004, government announced the slogan "from hospital-based treatment to community-based care" as the vision for reforming Mental Health Care. However, the number of psychiatric hospital beds and mean length of hospital stay remain high in Japan. 
In 2012, there were approximately three hundred forty thousand psychiatric hospital beds in Japan, with a mean length of hospital stay of approximately 280 days, which is high compared to various other countries. Furthermore, approximately 17\% (about 50,000) "social hospitalization patients" [1] are hospitalized in psychiatric departments but could be discharged if a more comprehensive system for accepting them existed. Therefore, an urgent issue in psychiatric care is transitional support for the discharge of social hospitalization patients and long-term inpatients.

In 1958, psychiatric day care was conducted as experimental research by the Japanese National Institute of Mental Health. In the early 1970s, it was instituted with the approval of the Ministry of Health. Most often, psychiatric day care is directed by medical institutions as part of standard medical practice. However, care consists primarily of psychosocial therapy and maintenance therapy and does not include acute care. In other words, it is difficult to treat day-care patients whose condition is unstable or who exhibit exacerbated psychiatric symptoms, and no such treatment structure has been established [2]. Accordingly, psychiatric day care in Japan exists as an outpatient rehabilitation center for individuals with mental illness who have completed hospital care. Therefore, psychiatric day care plays a key role as transitional support after discharge.

Psychiatric day care improves patient capacity in daily life and reduces negative symptoms, relapse, and re-hospitalization [3] [4] [5] [6]. Nevertheless, a high interruption rate is associated with short-term usage of psychiatric day care during the introductory period (i.e., from the introduction of treatment until group familiarity is established) [7]. In fact, more than half of day-care patients discontinue day care before they become familiar with it [8].

Prior studies have identified several reasons for discontinuation, including refusal to participate in groups and being made to do things beyond one's ability [7], high anxiety and interpersonal stress [9], and unclear objectives of day-care usage [10]. These studies were based on objective observations of medical care providers and limited questionnaire results. Accordingly, psychiatric day care has not been examined from the perspective of patients' experiences during the introductory period.

The high interruption rate of day-care patients during the introductory period is thought to be related to experiences specific to this period as patients adapt to a new environment. However, it remains unclear what kind of experiences day-care patients encounter during the introductory period.

Two critical principles underlie psychiatric rehabilitation: the practitioner's commitment to the goal of the individual person's involvement and the practitioner's belief that rehabilitation is done with persons and not to persons is critical [11]. Therefore, the subjective position and orientation of the individual concerned should be emphasized and so individuals' experiences cannot be disregarded.

Here, we aimed to elucidate the experiences of day-care patients during the 
introductory period. In doing so, we obtained feedback on why patients withdrew during the introductory period to help us reconsider the approach to care by medical care providers involved in the introductory period of psychiatric day care. More precisely, we conducted this study consistent with the philosophy of listening and providing rehabilitation to the individual concerned.

\section{Methods}

\subsection{Study Design}

The introductory period refers to the period of approximately $1-3$ months from the introduction of day care treatment until an attendee becomes familiar with the group [12]. Here, we defined the introductory period as the 3-month period starting from an attendee's first rehabilitation at a psychiatric day care center. The study sample consisted of patients who were in the introductory period of their first experience at psychiatric day care.

Data consisted of detailed narratives of situations involving complicated human relationships or human experiences. In qualitative research, truthful descriptions of events and phenomena serve as data and experiences and their significance to participants is explored by inductive reasoning [13] [14]. Accordingly, we determined that a qualitative descriptive study design best suited our purpose.

The descriptive design is to document various characteristics in populations of interest to nurses to gather data on those populations. In the development of nursing science, patient resources can be described and reported in taxonomies [15]. Moreover, once the data was analyzed and categories derived, we are able to report experiences common among those population.

\subsection{Participants}

We selected participants from groups that approximately thirty to fifty patients belong to, and obtained consent from 13 patients ( 8 males, 5 females). Mean age was $40.3 \pm 9.8$ years. The underlying mental illness was most commonly schizophrenia at five patients. There were seven patients who had been hospitalized, nine patients who cohabited with their family, and all patients had work experience. Furthermore, the day care facilities served individuals of various ages with various mental health disorders. Usage was not restricted by diagnosis or age (Table 1).

\subsection{Data Collection}

Managers of participating institutions received a written explanation of the study's purpose and methods. Study candidates were recruited through public notice board advertisements and introduced by institutional managers and attending physicians. After explaining the study to the candidates, we conducted semistructured interviews with those who provided consent. Interview guidelines 
Table 1. Overview of participants' characteristics.

\begin{tabular}{|c|c|c|c|c|c|c|c|c|}
\hline Participant & Age & Gender & $\begin{array}{l}\text { Psychiatric } \\
\text { Disability }\end{array}$ & Disease Duration & $\begin{array}{c}\text { Hospitalization } \\
\text { Experience }\end{array}$ & $\begin{array}{c}\text { Living } \\
\text { Arrangement }\end{array}$ & $\begin{array}{c}\text { Social Resources } \\
\text { Utilized }\end{array}$ & $\begin{array}{c}\text { Work } \\
\text { Experience }\end{array}$ \\
\hline A & $30 \mathrm{~s}$ & Female & Depression & $5+$ years but less than 10 years & No & $\begin{array}{l}\text { Living with } \\
\text { family }\end{array}$ & N/A & Yes \\
\hline B & $30 \mathrm{~s}$ & Female & $\begin{array}{l}\text { Developmental } \\
\text { disorder }\end{array}$ & $10+$ years but less than 15 years & Yes & $\begin{array}{l}\text { Living with } \\
\text { family }\end{array}$ & N/A & Yes \\
\hline $\mathrm{C}$ & $50 \mathrm{~s}$ & Male & Schizophrenia & $20+$ years but less than 25 years & No & Living alone & N/A & Yes \\
\hline $\mathrm{D}$ & $50 \mathrm{~s}$ & Male & Schizophrenia & $30+$ years but less than 35 years & Yes & Living alone & Home nurse visit & Yes \\
\hline $\mathrm{E}$ & $30 \mathrm{~s}$ & Female & Schizophrenia & Under 1 year & No & $\begin{array}{l}\text { Living with } \\
\text { family }\end{array}$ & N/A & Yes \\
\hline $\mathrm{F}$ & $10 \mathrm{~s}$ & Male & $\begin{array}{l}\text { Adjustment } \\
\text { disorder }\end{array}$ & $1+$ years but less than 5 years & No & $\begin{array}{l}\text { Living with } \\
\text { family }\end{array}$ & N/A & Yes \\
\hline G & $40 \mathrm{~s}$ & Male & Schizophrenia & Under 1 year & Yes & Living alone & $\begin{array}{c}\text { Employment } \\
\text { training }\end{array}$ & Yes \\
\hline $\mathrm{H}$ & $40 \mathrm{~s}$ & Female & Schizophrenia & $20+$ years but less than 25 years & Yes & $\begin{array}{l}\text { Living with } \\
\text { family }\end{array}$ & $\begin{array}{l}\text { Community } \\
\text { activity support } \\
\text { center }\end{array}$ & Yes \\
\hline I & $40 \mathrm{~s}$ & Female & Bipolar disorder & $1+$ years but less than 5 years & Yes & $\begin{array}{l}\text { Living with } \\
\text { family }\end{array}$ & $\begin{array}{l}\text { Employment } \\
\text { training }\end{array}$ & Yes \\
\hline $\mathrm{J}$ & $30 \mathrm{~s}$ & Male & $\begin{array}{l}\text { Adjustment } \\
\text { disorder }\end{array}$ & $1+$ years but less than 5 years & No & $\begin{array}{l}\text { Living with } \\
\text { family }\end{array}$ & N/A & Yes \\
\hline $\mathrm{K}$ & $30 \mathrm{~s}$ & Male & $\begin{array}{l}\text { Adjustment } \\
\text { disorder }\end{array}$ & $1+$ years but less than 5 years & Yes & Living alone & N/A & Yes \\
\hline $\mathrm{L}$ & $50 \mathrm{~s}$ & Male & Bipolar disorder & $15+$ years but less than 20 years & Yes & $\begin{array}{l}\text { Living with } \\
\text { family }\end{array}$ & $\begin{array}{l}\text { Employment } \\
\text { training }\end{array}$ & Yes \\
\hline M & $40 \mathrm{~s}$ & Male & Bipolar disorder & Under 1 year & No & $\begin{array}{l}\text { Living with } \\
\text { family }\end{array}$ & N/A & Yes \\
\hline
\end{tabular}

N/A, not applicable/availables.

included questions about: 1) personal background (age, gender, psychiatric disability, disease duration, hospitalization experience, living arrangement, social resources utilized, and work experience); 2) details of activities performed, thoughts, feelings, and events during the introductory period over time (e.g., "Please describe the events since you first started day care up to 3 months. Approximately when did you start attending day care? How did you feel at that time? What activities did you do? What were you worried about? What troubled you? What made you happy?"); and 3) relationships with individuals encountered during the introductory period. The survey was conducted between August 2014 and September 2014.

One-on-one interviews were conducted between a researcher and the participant in a private room. Narratives were recorded on an IC recorder and then transcribed verbatim.

\subsection{Data Analysis}

Data was analyzed using a qualitative descriptive approach according to content analysis guidelines by Yatsu [16]. First the transcribed interviews were read 
through several times. In the second, keeping in mind content relevant to the purpose of the study (i.e., experiences of day-care patients during the introductory period) and using each participant's words as much as possible, content was coded so as to be faithful to its meaning and then checked by a fellow researcher. We classified coded content by comparing similarities and differences, summarized them into several codes, labeled them, and then extracted categories and subcategories. Finally, during the categorization process, we returned to the data to check content validity to name the categories to show semantic content.

In addition, to satisfy confirmability, a member check was performed by experts specializing in psychiatric mental health nursing who have provided home care to individuals with mental disabilities.

\subsection{Ethical Considerations}

This study was approved by the ethical review board of Hamamatsu University School of Medicine (approval No. E14-081, dated July 29, 2014). Managers of participating institutions and participants were given written and oral explanations of the study's objectives and methods and the method of publishing its results. They were informed that participation was voluntary, that non-participation would have no impact on their medical and nursing care, that privacy of personal information would be protected, and that the interview content would be recorded. The study was conducted after obtaining written consent from all the managers and participants.

\section{Results}

\section{Experiences of Psychiatric Day-Care Patients during the Introductory Period}

The first experiences of psychiatric day-care patients during the introductory period were that patients were confused about their attitude because they paid attention to themselves, and consequently closed their involvement with others (early introductory period). However, through therapeutic day care activities, they attempted to adapt themselves and gradually turned their attention toward others and accumulated interpersonal experiences (mid-introductory period). As interactions with others became more frequent, they became conscious of themselves and others. Finally, while having worries about the future, they looked toward recovery and became aware that they were changing (late introductory period).

Nine categories and 32 subcategories were identified. Below, categories are indicated by brackets, subject narratives by italics, and subject type by parentheses. Categories were also organized by early, mid-, and late introductory periods (Table 2).

\section{1) Early Introductory Period}

Patient interest was self-focused, and so they felt confused and shut themselves off from others. 
Table 2. Categories of experiences of psychiatric day care patients during the introductory period.

\begin{tabular}{|c|c|c|}
\hline Period & Categories & Subcategories \\
\hline \multirow{10}{*}{$\begin{array}{l}\text { Early } \\
\text { introductory } \\
\text { period }\end{array}$} & \multirow{3}{*}{$\begin{array}{l}\text { They felt lost having to cope } \\
\text { with new experiences }\end{array}$} & They could not imagine their day care life in future \\
\hline & & They didn't know what to do or where to go \\
\hline & & They wondered about who they should eat lunch with \\
\hline & \multirow{4}{*}{$\begin{array}{l}\text { They had distress through } \\
\text { communication }\end{array}$} & They were at a loss when someone tried talking to them \\
\hline & & They thought that it was difficult to talk to other patients who have mental disorders \\
\hline & & They agonized unable to become familiar with other patients \\
\hline & & They became nervous when they spoke in front of other people \\
\hline & \multirow{3}{*}{$\begin{array}{l}\text { They were cutting themselves } \\
\text { off from others }\end{array}$} & They tried not to stand out \\
\hline & & They could not become familiar with staff and other patients and spent to keep themselves \\
\hline & & They could not talk to others voluntarily \\
\hline \multirow{13}{*}{$\begin{array}{l}\text { Mid- } \\
\text { introductory } \\
\text { period }\end{array}$} & \multirow[t]{5}{*}{ They were attempting to adapt } & They thought that day care was their only option to prevent the exacerbation of symptoms \\
\hline & & They chose some treatment program that they wanted to try \\
\hline & & They carried out some useful treatment program in their life \\
\hline & & $\begin{array}{l}\text { Although they were reluctant to join the treatment program, it went well when they joined } \\
\text { an activity }\end{array}$ \\
\hline & & $\begin{array}{l}\text { When they didn't feel well, they adjusted their activities in the treatment program to make it } \\
\text { more relaxing }\end{array}$ \\
\hline & \multirow{2}{*}{$\begin{array}{l}\text { They felt relief at being spoken } \\
\text { to by surrounding people }\end{array}$} & They felt reassured when other patients talked to them \\
\hline & & They felt that staff talked to them and cared about them \\
\hline & \multirow{6}{*}{$\begin{array}{l}\text { They gradually formed } \\
\text { connecting with others }\end{array}$} & They slowly started to listen to the people around them \\
\hline & & When they asked staff about treatment program content, they were answered with kindness \\
\hline & & They could talk to staff and other patients, although they were a little hesitant to do so \\
\hline & & They could mutually share their troubles, and so support each other \\
\hline & & They could find out about the thinking of various other people \\
\hline & & It was fun to cook together while talking with everyone \\
\hline \multirow{9}{*}{$\begin{array}{l}\text { Late } \\
\text { introductory } \\
\text { period }\end{array}$} & \multirow{2}{*}{$\begin{array}{l}\text { They had worries about their } \\
\text { obscure future }\end{array}$} & They realized that recovery took more time than they had expected \\
\hline & & They questioned the implication of staying in day care as was \\
\hline & \multirow{3}{*}{$\begin{array}{l}\text { They broadened their daily life } \\
\text { activities }\end{array}$} & They stepped up by increasing the number of treatment programs to participate in \\
\hline & & They could expand their capacities and enjoyed going out \\
\hline & & They tried to do what they had learned at the day care and were praised by their family \\
\hline & \multirow{4}{*}{$\begin{array}{l}\text { They exhibited awareness of } \\
\text { recovery }\end{array}$} & They could regulate their life and eating habits \\
\hline & & They could live an unhurried life in a comfortable atmosphere \\
\hline & & They gradually became healthy as they shared laughs with various people \\
\hline & & They could envision challenges and hopes \\
\hline
\end{tabular}

[Feeling lost having to cope with new experiences] referred to participants entering a new place, being surrounded by people that they are meeting for the first time, and thus being at a loss as to the correct way to behave, and being unable to imagine their day-care life in the future. 
For instance, in sitting areas, I did not know where I should sit. At meetings etc., I didn't know what to do before the activities started, and during free time, I didn't know where I should go (A).

[Distress through communication] referred to the awareness of being bad at and having trouble with communication for creating new relationships with day-care patients, and because other day-care patients were individuals with similar mental handicaps.

I didn't know how to mingle. With some people, I could adapt, but with others I couldn't. Having to adapt to various people caused me distress $(\mathrm{H})$.

The people attending day care had various types of symptoms, and some people had different symptoms from mine, and it was hard to talk to them because I didn't know how I should talk. I was particularly mindful about the other day-care patients $(\mathrm{K})$.

[Cutting themselves off from others] referred to fear of being an annoyance to others, or that through relationships with others, they would get hurt. Consequently, participants protected themselves by not getting involved with others.

I don't know how to express my feelings, so I would hide in my own shell, and keep my guard up. But that (coming out of my shell) scared me, and I couldn't do it $(\mathrm{A})$.

There were quite a few older patients, so I am kind of careful and keep a low profile. I would stand at the back and smoke cigarettes to not stand out, and when I talk, I try not to anyone (D).

\section{2) Mid-Introductory Period}

Turning one's attention toward others led to relationships with others while having relief.

[Attempting to adapt] referred to entering a self-selected therapeutic activity that was suited to one's physical condition and, while thinking that they only have day care for recovery, they tried to adapt.

I came to day care after consulting my physician, who recommended the service. I thought that it was the only path I could take, and so I had no choice but to go on and step it up $(\mathrm{K})$.

I thought I would try ceramic art, but it looked hard. The easiest activity was karaoke. I thought, I could sing because I used to sing at snack bars, and so I gave it a shot (C).

[Relief at being spoken to by surrounding people] referred to feeling at ease when spoken to by day-care staff and patients.

Usually when spoken to, I realize that, hey, this person is not my enemy, and my sense of fear dissipates (A).

[Gradually forming connections with others] referred to the feeling that a mutual relationship is developing between oneself and the other person, and the connection is shared, which gives pleasure and emotional support.

I had never selected and made a meal together as a group, and I really enjoyed it. Chopping (the ingredients) while chatting with everyone and cooking together was a new experience for me (E). 
I had depression, but everybody else was sick too, and so in a way, I acquired a sense of self-esteem. Because everybody shared similar problems, it was kind of easy to talk (B).

\section{3) Late Introductory Period}

Connections with others led to awareness of oneself and others, and while worrying about the future and looking toward recovery, participants realized that they were changing.

Being [worried about their obscure future] referred to anxiety about the future after reflecting on their current situation.

I wondered if I should be happy with my life as is, and felt as though I would be here my whole life. I had too much of a good thing and wondered if I should just keep lazing about as is $(\mathrm{H})$.

[Broadened their daily life activities] referred to the expansion of the range of day-care activities and community life activities.

Because I have day care, I felt glad to go into town, and I looked forward to window shopping, etc. Sometimes I felt or realized that this (going out) was important $(\mathrm{H})$.

(Because I had cooked at day-care activities) I also cooked at home. I was told (my wife told me) that my cooking was good. Her reaction was good, wasn't it? (L).

[Awareness of recovery] referred to becoming aware of moving in a positive direction from both social and psychological aspects.

I am confident in the rhythm that my life has taken. I am now able to get up every morning at the same hour. Before, when I didn't come (to day care), I would get up at any odd hour (K).

When playing games with everyone, slowly but surely, they would make me really happy. Coming here made my fears go away(J).

\section{Discussion}

\subsection{Change in Orientation of the Patients' Attention}

During the introductory period, patients were initially self-focused, which we believe was their response to the uncertainty in their surrounding environment (i.e., the day care), where they were at a loss as how to behave. Anyone placed in a new environment would experience some confusion and distress. Day-care patients in this study characteristically shut themselves off from others for self-protection. This was evident in the patients' narratives. However, we believe that the patients protect themselves for fear of getting hurt during interpersonal interactions. Therefore, we are required to keep in mind that experiences of day care patients affect the interruption of day care.

Most mentally handicapped people have limited interpersonal relationships and have experienced distress and frustration in their past and present relationships, thus deepening their self-perception of inadequacy [17]. In fact, failure to 
interact with others would cause them no additional harm, which in a sense protects them. Accordingly, we believe that day-care patients were compelled to withdraw from others to protect themselves in order to survive in the new environment.

Therapeutic day-care activities include cooking, ceramic arts, sports, social skills training, and psychoeducation. Patients selected and joined in the therapeutic activities. Participation puts patients in a situation where they are forced to interact with others, that is, relief arising from interpersonal interactions and experiencing a connection with others.

By turning their interest toward others, day-care patients could not only observe the current state of others, but understand them with sympathy. In interpersonal relationships, harboring relief implies that one is genuinely sympathetic and facing another person. Therapeutic activities help day-care patients integrate naturally into a group. Therefore, we believe that these activities enable day-care patients to turn their attention away from the self and toward others.

As interactions developed, day-care patients began to ponder their current situation and asking themselves if life was good just the way it was. As they experienced anxiety about the future and broadened their daily life activities, they began to realize that they were recovering. That is, day-care patients expressed this fact through others as they had become aware of themselves and others. According to Buber [18], when two people meet face-to-face and every time each is recognized by the other as a human being, the self is exposed. Thus, in becoming aware of the self and the other, day-care patients gained self-understanding.

One could say that questioning oneself and realizing that recovery implies discovery of one's abilities is an experience of recovery [19]. Furthermore, individuals using mental health services perceive recovery to be an ongoing quest in life [20]. When using day-care services for the first time, day-care patients questioned the new environment, their relationships with others, and the situation in which they had been placed. Accordingly, subsequent experiences during the introductory period shaped the process of questioning life toward recovery. In the introductory period, exploring this process together with patients ultimately gave meaning to their use of day care.

\subsection{Significance of Psychiatric Day Care for the Group}

In Japan, based on a policy shift from hospital-based treatment to community-based care, medical care and welfare is provided to support community life for persons with mental disabilities after discharge, such as outreach support and welfare services. In particular, psychiatric home-visit nursing, a typical outreach support, has been found to effectively reduce relapse [21] and shorten the length of hospital stays (days) [22]. On the other hand, psychiatric day care also targets the same individuals who receive home care. However, a major difference of outreach support is that treatment is conducted in a group. That is, support through psychiatric home-visit nursing care involves a relationship essentially between 
two individuals, the patient and the nurse, with other individuals limited to family members. Psychiatric day care is provided through group activities. Thus, the patient of psychiatric day care is expected to connect not only with medical care providers, but also with other individuals who have similar conditions.

During the early introductory period, some patients appeared to shut themselves off from others. However, by the mid-period, they harbored relief in their interpersonal relationships and began to connect with others. Connecting with others helped patients understand how various people think and how to share other people's troubles and provide moral support. This demonstrates interpersonal learning and universality, which are factors of group therapy as defined by Yalom and Leszcz [23].

By the late introductory period, patients' daily life activities broadened and they gained insight on their problems and hopes. This demonstrates development of socializing techniques and the instillation of hope [23]. Thus, experiences related to group therapy factors were identified during the introductory period of day care.

Participants in the present study were individuals using day care for the first time. Although the group was homogeneous, it was not, strictly speaking, linked. In general, a homogeneous group often indicates patients sharing a diagnosis. A homogeneous group based on diagnosis fulfills the specific needs of the patients [24], and short-term homogeneous groups prevent early discontinuation and give rise to early cohesiveness [25]. Group cohesiveness refers to helping one another achieve a specific goal. However, we did not find patients' experiences that expressed this cohesiveness.

In Japan, almost all day-care is used by individuals with chronic schizophrenia, and a few day-care centers provide treatment segregated by diagnosis. In this study, patients belonged to groups of individuals with various diagnoses. In the future, we need to comparatively analyze the experiences of patients in the introductory period and in homogeneous groups.

\subsection{Choice of Daily Life Setting to Open Possibilities}

In studies on the effects of psychiatric day hospitals conducted in various countries overseas, day care might improve coping knowledge despite not being associated with recurrence [26] and day hospital care may help avoid inpatient care but it is unconvincing about the evidence of effects [27].

Day hospitalization (a.k.a. partial hospitalization) is a proactive treatment program in the U.S. that is an alternative to hospitalization, including acute care, and is structured as a time-limited attending hospital. Although day care in Japan is similarly structured given that treatment programs take place at a time-limited hospital, does not include acute care. Although U.S. day hospitals and Japanese day care are not the same, we see no difference in the need for day-care treatment, effective treatment programs, and adequate performance of empirical research [12]. 
In this study, we learned that patients utilized psychiatric day care in the mistaken belief that it was the only option available to prevent exacerbation of their symptoms. Furthermore, as they became aware of their changes toward recovery, some individuals questioned the proposition of remaining in day care. $\mathrm{Al}-$ though day care serves as rehabilitation, day care alone does not prevent the exacerbation of symptoms. Accordingly, individuals should be recommended to follow a different path when appropriate.

Although further study is needed to determine what causes patients to believe that day care is the only option to prevent symptom exacerbation, patients should always collaborate with nurses to determine whether psychiatric day care can serve as a support to push them along the road to recovery, to identify other places that might open up life's possibilities for them, and above all, to support their ability to make choices.

Therefore, by elucidating the experiences of psychiatric day-care patients during the introductory period, we hope that nurses providing psychiatric day care will not focus on preventing patients from discontinuing treatment during the introduction period, but rather collaborate with day-care patients to help them find the right setting so that those who do need rehabilitation through day care will continue treatment.

\section{Conclusions}

Individuals using psychiatric day care for the first time felt lost during the introductory period, were self-focused, and closed themselves off from others. Nevertheless, through therapeutic activities at day care, over time they turned their attention toward others, connected with others, and in doing so became aware of themselves and others. These experiences helped them realize changes in themselves toward recovery, formed the process necessary for recovery, and gave meaning to their use of day care. Thus, the findings of this study can provide future day-care patients with useful information about prior patients' experiences, thereby reducing anxiety over uncertainty over the use of day care and increasing trust in day care.

In this study, patients are not a homogeneous population such as the same psychiatric disability. Therefore, the findings cannot be generalized to other populations.

\section{Acknowledgements}

The authors are very grateful to all the participants and cooperating facilities. This research was supported in part by JSPS KAKENHI Grant-in-Aid for Young Scientists (B) (no. 26870253) from the Japan Society for the Promotion of Science, Tokyo, Japan. The authors presented part of this article at the $4^{\text {th }}$ World Academy of Nursing Science meeting in October 2015 in Hannover.

\section{Conflicts of Interest}

The authors declare no conflicts of interest regarding the publication of this paper. 


\section{References}

[1] Ministry of Health, Labour and Welfare (2015) The 1st Meeting for Studying the Future of Mental Health and Medical Welfare Document.

https://www.mhlw.go.jp/file/05-Shingikai-12201000-Shakaiengokyokushougaihoke nfukushibu-Kikakuka/0000108755_12.pdf

[2] Ministry of Health, Labour and Welfare (2016) Mental Health Commission Project Tōshin. http://dl.med.or.jp/dl-med/teireikaiken/20160608_5.pdf

[3] Kitamura, T., Kozai, M., Tanimoto, C., Higa, C., Suzuki, H. and Isao, T. (2008) The Effects of Psychiatric Clinic Day Care on Psychiatric and Living Competency Among Outpatients. Japanese Journal of Clinical Psychiatry, 37, 405-413.

[4] Asano, H. (1993) Evaluation and Efficacy of Day Treatment: Effect on the Prevention of Readmission. Japanese Journal of Clinical Psychiatry, 22, 61-67.

[5] Takeda, T. and Omori, B. (1992) The Efficacy of Day Care in Preventing the Readmission of Chronic Schizophrenic Patients. Psychiatria et Neurologia Japonica, 94, 350-362.

[6] Ikebuchi, E. and Noto, M. (1999) Partial Hospitalization for Schizophrenia. Teikyo Medical Journal, 26, 373-382.

[7] Ikebuchi, E., Miyauchi, M., Anzai, N., Kumagai, N. and Sano, I. (1992) Research on Dropouts from Day Treatment at the Early Therapeutic Stage. The Official Journal of the Japan Association of Group Psychotherapy, 8, 167-173.

[8] Ikebuchi, E. and Anzai, N. (1995) How Can We Improve the Therapeutic System of Partial Hospitalization in the Latter Half of the 1990s in Japan? Clinical Psychiatry, 37, 908-919.

[9] Isoishi, E., Mishina, H., Sugimoto, H. and Suzuki, M. (2000) Examination of Psychiatric Day Care for Users. The Journal of Iwamizawa Municipal General Hospital, 26, 71-76.

[10] Tajika, A., Sugiyama, M., Fukushima, M., Murakami, T., Hattori, Y., Kakinaga, K., et al. (2005) Factors Associated with Dropout from Day Care. The Japanese Journal of Psychiatry, 10, 409-416.

[11] Anthony, W., Cohen, M., Farkas, M. and Gange, C. (2002) Psychiatric Rehabilitation. 2nd Edition, Nonaka, T., Ohashi, H., Translators, Boston University, Boston, 83-103.

[12] Ikebuchi, E. (2006) Day Treatment. Japanese Journal of Clinical Psychiatry, 35, 525-530.

[13] Gregg, M., Asahara, K. and Yokoyama, Y. (2007) Yokuwakaru Shitsutekikenkyu-No Susumekata Matomekata Kangokenkyu-No Ekisupa-to Mezashite. Ishiyaku Publishers, Tokyo, 56-59.

[14] Polit, D.F. and Beck, C.T. (2004) Nursing Research: Principles and Methods. 7th Edition, Kondo, J., Translate, Lippincott Williams \& Wilkins, Philadelphia, 250-269.

[15] Brink, P.J. and Wood, M.J. (1998) Advanced Design in Nursing Research. 2nd Edition, Sage Publications Ltd., Thousand Oaks.

[16] Yatsu, H. (2013) Start Up Shitsuteki Kango Kenkyu. Gakken, Tokyo.

[17] Rapp, C.A. and Goscha, R.J. (2011) The Strengths Model: A Recovery-Oriented Approach to Mental Health Services. 3rd Edition, Tanaka, H., Translate, Oxford University Press, Oxford, 97.

[18] Buber, M. (1948) Ningen-Toha Nanika (Kojima, H., Translators). Risosha, Tokyo. 
[19] de Wet, A., Swartz, L. and Chiliza, B. (2015) Hearing Their Voices: The Lived Experience of Recovery from First-Episode Psychosis in Schizophrenia in South Africa. International Journal of Social Psychiatry, 61, 27-32. https://doi.org/10.1177/0020764014535753

[20] Kidd, S., Kenny, A. and McKinstry, C. (2015) The Meaning of Recovery in a Regional Mental Health Service: An Action Research Study. Journal of Advanced Nursing, 71, 181-192. https://doi.org/10.1111/jan.12472

[21] Ogata, A., Mimura, K., Konno, E., Fukuda, M., Yamamoto, T., Fujita, E., et al. (1997) The Study of Home Visitation Psychiatric Care in the Prevention of Schizophrenic Relapse. Clinical Psychiatry, 39, 131-137.

[22] Kayama, M., Matsushita, T., Funakoshi, A., Tochii, A., Sawada, A., Setoya, N., et al. (2005) Effectiveness of Home Visits by Psychiatric Nurses: An Empirical Study Using Psychiatric Length of Stay as an Outcome Measure. Clinical Psychiatry, 47, 647-653.

[23] Yalom, I.D. and Leszcz, M. (2005) The Theory and Practice of Group Psychotherapy. 5th Edition, Basic Books, New York.

[24] Larivière, N., Melançon, L., Fortier, L., David, P., Cournoyer, J., Baril, M.C., et al. (2009) A Qualitative Analysis of Clients' Evaluation of a Psychiatric Day Hospital. Canadian Journal of Community Mental Health, 28, 165-179. https://doi.org/10.7870/cjcmh-2009-0013

[25] Yalom, I.D. (1995) The Theory and Practice of Group Psychotherapy. 4th Edition, Basic Books, New York.

[26] Foster, J.H. and Jumnoodoo, R. (2008) Relapse Prevention in Serious and Enduring Mental Illness: A Pilot Study. Journal of Psychiatric \& Mental Health Nursing, 15, 552-561. https://doi.org/10.1111/j.1365-2850.2008.01265.x

[27] Shek, E., Stein, A.T., Shansis, F.M., Marshall, M., Crowther, R. and Tyrer, P. (2009) Day Hospital versus Outpatient Care for People with Schizophrenia. The Cochrane Database of Systematic Reviews, 4, CD003240.

https://doi.org/10.1002/14651858.CD003240.pub2 